\title{
Incorporating patient preferences into osteoarthritis treatment
}

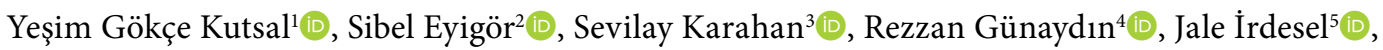 \\ Merih Sarıdoğan ${ }^{6}\left(\mathbb{D}\right.$, Pınar Borman $^{7}$ (D), Aylin Sarı ${ }^{8}$ (D), Kutay Ordu Gökkaya ${ }^{9}$, Vildan Binay Safer ${ }^{10} \mathbb{C}$ \\ ${ }^{1}$ Department of Physical Medicine and Rehabilitation, Hacettepe University, Faculty of Medicine, Ankara, Turkey \\ ${ }^{2}$ Department of Physical Medicine and Rehabilitation, Ege University, Faculty of Medicine, Izmir, Turkey \\ ${ }^{3}$ Department of Biostatistics, Hacettepe University, Faculty of Medicine, Ankara, Turkey \\ ${ }^{4}$ Department of Physical Medicine and Rehabilitation, Medical Park Izmir Hospital, Izmir, Turkey \\ ${ }^{5}$ Department of Physical Medicine and Rehabilitation, Uludağ University, Faculty of Medicine, Bursa, Turkey \\ ${ }^{6}$ Department of Physical Medicine and Rehabilitation, Istanbul University Cerrahpaşa, Cerrahpaşa Faculty of Medicine, Istanbul, Turkey \\ ${ }^{7}$ Department of Physical Medicine and Rehabilitation, Ministry of Health Ankara City Hospital, Ankara, Turkey \\ ${ }^{8}$ Department of Physical Medicine and Rehabilitation, Erenköy Physical Therapy and Rehabilitation Hospital, Istanbul, Turkey \\ ${ }^{9}$ Department of Physical Medicine and Rehabilitation, Ministry of Health Gaziler Physical Medicine and Rehabilitation \\ Training and Research Hospital, Ankara, Turkey \\ ${ }^{10}$ Department of Physical Medicine and Rehabilitation, Sancaktepe Şehit Prof. Dr. Ilhan Varank Training and Research Hospital, Istanbul, Turkey
}

\begin{abstract}
Objectives: This study aims to identify the relationship between treatment modalities and the patients' preferences in osteoarthritis (OA) treatment and identify the related factors.

Patients and methods: This multi-center, cross-sectional study included a total of 305 patients with OA (66 males, 239 females; mean age: $66.4 \pm 9.7$ years; range, 38 to 90 years) between July 2019 and January 2020. Data including demographic and clinical characteristics of the patients were recorded using a structured questionnaire.

Results: The mostly common involvement sites were knee joints, lumbar, and cervical regions, respectively. Prior to the study, the treatment modalities which were prescribed to patients were oral drugs (79.7\%), topical drugs (73.8\%), home-based exercise program (62.6\%), and physical therapy (outpatient) (61.3\%). Of the recommended remedy, $89.2 \%$ were prescribed by physiatrists, $24.6 \%$ by orthopedists, $5.6 \%$ by family practitioners, $2.6 \%$ by neurosurgeons, and $1.6 \%$ by algologists. The most beneficial treatments (to whom) were inpatient physical therapy program $(47 \%)$, oral drugs (41\%), home-based exercise programs (24.9\%) according to patients' perspective. According to patient preferences, nearly half of the patients preferred outpatient physical therapy program (45.9\%), oral drugs (33.1\%), inpatient physical therapy (20\%), and home-based exercises (18\%). The most common reasons for their preferences were previous benefits from treatment (54.4\%), long-term effects (38\%), easy access to treatment $(33.1 \%)$ and concerns about side effects (28.9\%). The mostly common reasons for their preferences were previous benefits from the treatment $(54.4 \%)$, long-term positive effects of physical therapy (38\%), easy access to the treatment $(33.1 \%)$ and concerns about side effects of drugs (28.9\%).

Conclusion: Besides medical regimen, the results of this study showed that the patients preferred outpatient and inpatient physical therapy modalities, and home-based exercises programs. In the light of these findings, initiation of a new prescription (e.g., drugs or physical therapy modalities) in OA patients, previous treatment modalities, and approaches are suggested to be carefully reviewed by the clinician to anticipate and improve the adherence behavior to the new treatment.
\end{abstract}

Keywords: Medication, osteoarthritis, rehabilitation, treatment.

Received: June 22, 2020 Accepted: March 22, 2021 Published online: October 18, 2021

Correspondence: Sibel Eyigör, MD. Ege Üniversitesi Tıp Fakültesi Fiziksel Tıp ve Rehabilitasyon Anabilim Dalı, 35100 Bornova, İzmir, Türkiye. Tel: +90232 - 3903687 e-mail: eyigor@hotmail.com

\section{Citation:}

Gökçe Kutsal Y, Eyigör S, Karahan S, Günaydın R, İrdesel J, Sarıdoğan M, et al. Incorporating patient preferences into osteoarthritis treatment. Arch Rheumatol 2021;36(4):577-586.

(02021 Turkish League Against Rheumatism. All rights reserved.

This is an open access article under the terms of the Creative Commons Attribution-NonCommercial License, which permits use, distribution and reproduction in any medium, provided the original work is properly cited and is not used for commercial purposes (http://creativecommons.org/licenses/by-nc/4.0/). 
Osteoarthritis (OA) is one of the most common long-term conditions, causing significant impairment of physical function. It can affect several joints associated with pain and functional limitation and is a leading cause of disability and participation restriction, particularly among older individuals. ${ }^{1,2}$ According to the literature, the prevalence of OA among people aged 45 and over varies between 20 and 35\%.3.4 Regarding the therapeutic approach, in the light of the evidence, 11 titles of recommendations were developed: the first seven titles were applicable to each patient in every stage of the disease and remaining were relevant for defined specific clinical situations. ${ }^{5}$ Different response in different localizations of the disease complicates the therapeutic choice further. Pharmacological management of OA includes agents for control of pain and inflammation, and group of oral slow-acting drugs and intraarticular hyaluronic acid. ${ }^{6}$ Non-pharmacological management includes physical therapy, assistive devices, and orthoses. Of note, it is known that patients are more satisfied with multimodal treatment modalities (combination of pharmacological and non-pharmacological modalities). ${ }^{5}$ However, there may be a gap between satisfaction of the patient and the deemed appropriate prescription at this point, and disagreement between preferences of patients and physicians becomes more important. ${ }^{7}$ To the best of our knowledge, no studies have assessed patient preferences by considering medical and non-medical different therapeutic options in OA treatment, yet. ${ }^{8-11}$

As described by Hiligsmann et al., ${ }^{12}$ there has been an advancing interest in assessing patients' preferences for healthcare treatments. This approach is defined as "preference-sensitive". Since OA is a non-fatal and chronic disease, its treatment can be easily adapted to the preferencesensitive therapeutic approach. ${ }^{12,13}$ Insights into the preferences of patients would be useful to optimize policy and clinical decision making through healthcare decision making that better reflects patients' preferences. ${ }^{12}$ In the present study, we aimed to investigate the patient preferences in OA treatment, since preferencesensitive treatments may play a critical role in adherence, particularly in chronic diseases such as OA.

\section{PATIENTS AND METHODS}

This multi-center, cross-sectional study was conducted by the Geriatric Rehabilitation Research Group of The Turkish Society of Physical Medicine and Rehabilitation (TSPMR). A total of 305 patients with OA (66 males, 239 females; mean age: $66.4 \pm 9.7$ years; range, 38 to 90 years) at Physical Medicine and Rehabilitation (PMR) outpatient clinics from Ankara, Izmir, Bursa, and Istanbul provinces of Turkey were included between July 2019 and January 2020. The sample size was determined pragmatically with all patients agreeing to be involved in the study. All patients were diagnosed as $\mathrm{OA}$ according to the 2019 American College of Rheumatology (ACR) classification criteria. ${ }^{14,15}$ Almost all the previous guidelines about concerning the treatment of OA have emphasized that pharmacological and non-pharmacological treatments should be combined and these combinations should be individualized for each patient. ${ }^{5}$ Based on this statement, patients were enrolled using the following inclusion criteria: (i) receiving treatment with at least one type of therapy for $\mathrm{OA}$; pharmacological, non-pharmacological treatments including any systemic and local medications, physical therapy, exercises, assistive devices, orthoses, injections, etc.; (ii) giving a written informed consent. Exclusion criteria were as follows: (i) having a diagnosis of psychiatric disorder and receiving psychiatric treatments and cognitive dysfunctions; (ii) inability to read and understand the questionnaires; and (iii) having any significant comorbidity (e.g., advanced cancer, stroke, unstable renal and hepatic deficiency). A written informed consent was obtained from each patient. The study protocol was approved by the Hacettepe University Ethics Committee (2019/18, GO 19/743, 2019/18-06). The study was conducted in accordance with the principles of the Declaration of Helsinki.

The questionnaire used in the study was constituted by PMR specialists who have experience in treatment and rehabilitation of geriatric OA patients for more than five years. It was designed as a structured questionnaire to assess demographic properties (age, sex, education, job, living area and medical comorbidities, social security, income, vacation habits, reading, and computer 
usage information), disease characteristics (affected joints, duration of disease, previous therapies, beneficial therapies), treatment preferences (oral and topical drugs, outpatient physical therapy, inpatient physical therapy, home-based exercise program, supervised exercise program (hospital), intraarticular drug approaches (steroid, platelet-rich plasma, hyaluronic acid, prolotherapy, ozone), acupuncture, dry needling, manipulation, use of assistive devices surgical prostheses, etc.) and the reasons for preferences (previous treatment effect, reimbursement, easy-access to treatment, long-term effect of treatment, side effects of treatment, benefit from

Table 1. Demographic and clinical data of patients $(n=305)$

\begin{tabular}{|c|c|c|c|c|}
\hline & $\mathrm{n}$ & $\%$ & Mean \pm SD & Min-Max \\
\hline Age (year) & & & $66.4 \pm 9.7$ & $38-90$ \\
\hline Height (m) & & & $161.0 \pm 8.6$ & $140-187$ \\
\hline Weight $(\mathrm{kg})$ & & & $75.7 \pm 13.2$ & $47-123$ \\
\hline Body mass index $\left(\mathrm{kg} / \mathrm{m}^{2}\right)$ & & & $29.4 \pm 5.5$ & $15.70-48.05$ \\
\hline $\begin{array}{l}\text { Sex } \\
\quad \text { Female } \\
\text { Male }\end{array}$ & $\begin{array}{c}239 \\
66\end{array}$ & $\begin{array}{l}78.4 \\
21.6\end{array}$ & & \\
\hline $\begin{array}{l}\text { Duration of disease (year) } \\
\quad 0-2 \\
2-5 \\
5-10 \\
10-15 \\
15-20\end{array}$ & $\begin{array}{l}47 \\
65 \\
88 \\
60 \\
45\end{array}$ & $\begin{array}{l}15.4 \\
21.3 \\
28.9 \\
19.7 \\
14.8\end{array}$ & & \\
\hline $\begin{array}{l}\text { Education } \\
\text { Illiterate } \\
\text { Primary School 1-5 } \\
\text { Primary School 6-8 } \\
\text { High School } \\
\text { College } \\
\text { University }\end{array}$ & $\begin{array}{c}36 \\
113 \\
37 \\
55 \\
22 \\
42\end{array}$ & $\begin{array}{c}11.9 \\
37 \\
12.2 \\
18.2 \\
7.3 \\
13.9\end{array}$ & & \\
\hline $\begin{array}{l}\text { Job } \\
\text { Worker } \\
\text { Officer } \\
\text { Farmer } \\
\text { House wife } \\
\text { Other } \\
\text { Retired }\end{array}$ & $\begin{array}{c}12 \\
10 \\
4 \\
153 \\
14 \\
112\end{array}$ & $\begin{array}{c}4.0 \\
3.3 \\
1.3 \\
50.5 \\
4.6 \\
37.0\end{array}$ & & \\
\hline $\begin{array}{l}\text { Living area } \\
\text { Centrum of the city } \\
\text { Suburban } \\
\text { Town } \\
\text { Village }\end{array}$ & $\begin{array}{c}269 \\
18 \\
10 \\
8\end{array}$ & $\begin{array}{l}88.2 \\
5.9 \\
3.3 \\
2.6\end{array}$ & & \\
\hline $\begin{array}{l}\text { Social security } \\
\text { Governmental } \\
\text { Private } \\
\text { No social security } \\
\text { Unknown }\end{array}$ & $\begin{array}{c}275 \\
19 \\
5 \\
6\end{array}$ & $\begin{array}{c}92.0 \\
6.4 \\
1.7 \\
1.96\end{array}$ & & \\
\hline $\begin{array}{l}\text { Income/month (Turkish lira) } \\
1000-2000 \\
2000-5000 \\
5000 \text { and up }\end{array}$ & $\begin{array}{c}87 \\
165 \\
45\end{array}$ & $\begin{array}{l}29.3 \\
55.6 \\
15.2\end{array}$ & & \\
\hline Summer vacation habit (yes) & 144 & 47.2 & & \\
\hline Habit of reading books (yes) & 140 & 45.9 & & \\
\hline Habit of using computer (yes) & 72 & 23.6 & & \\
\hline Chronic diseases (yes) & 235 & 77.0 & & \\
\hline
\end{tabular}




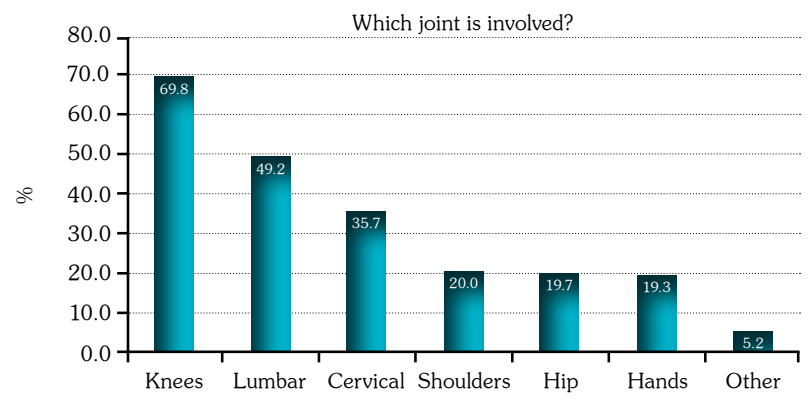

Figure 1. Sites of joint involvements of patients.

treatment, recommendation of treatment by a friend). The questionnaire was pre-tested in a small elderly OA patient population $(n=10)$ to ensure its comprehensiveness prior to the study. Interviews with the patients showed that all the indices were clear and the instrument was understandable. The questionnaire was, then, sent to the researchers in each center and administered by face-to-face interviews.

\section{Statistical analysis}

Statistical analysis was performed using the
IBM SPSS for Windows version 23.0 software (IBM Corp., Armonk, NY, USA). Continuous variables were expressed in mean \pm standard deviation or median (min-max), while categorical variables were expressed in number and frequency. Categorical variables were compared using the chi-square test or Fisher exact test. A $p$ value of $<0.05$ was considered statistically significant.

\section{RESULTS}

Demographic characteristics of the patients are presented in Table 1. Considering the affected joints, the most common involvement parts were determined as knee joints, lumbar, and cervical regions with rates of $69.8 \%, 49.2 \%, 35.7 \%$, respectively (Figure 1). The patients received oral drugs (79.7\%), topical drugs (73.8\%), homebased exercise program (62.6\%), and outpatient physical therapy (61.3\%) at hospital previously (Figure 2). Of the prescribed treatments, 89.2\% were recommended by physiatrists, $24.6 \%$ by orthopedists, $5.6 \%$ by family practitioners, $2.6 \%$ by neurosurgeons, and $1.6 \%$ by algologists. The

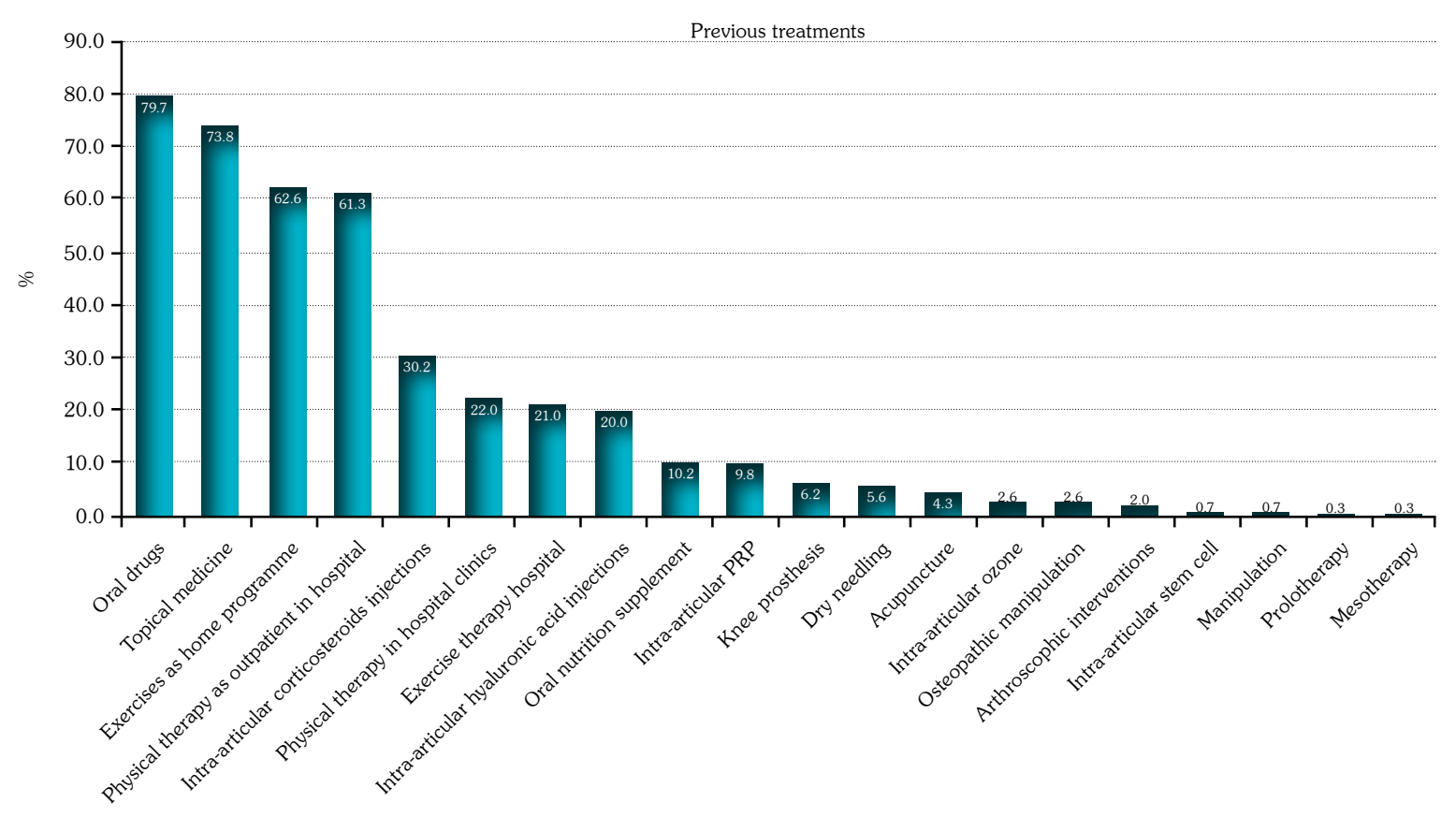

Figure 2. Previous treatments of patients. PRP: Platelet-rich plasma. 


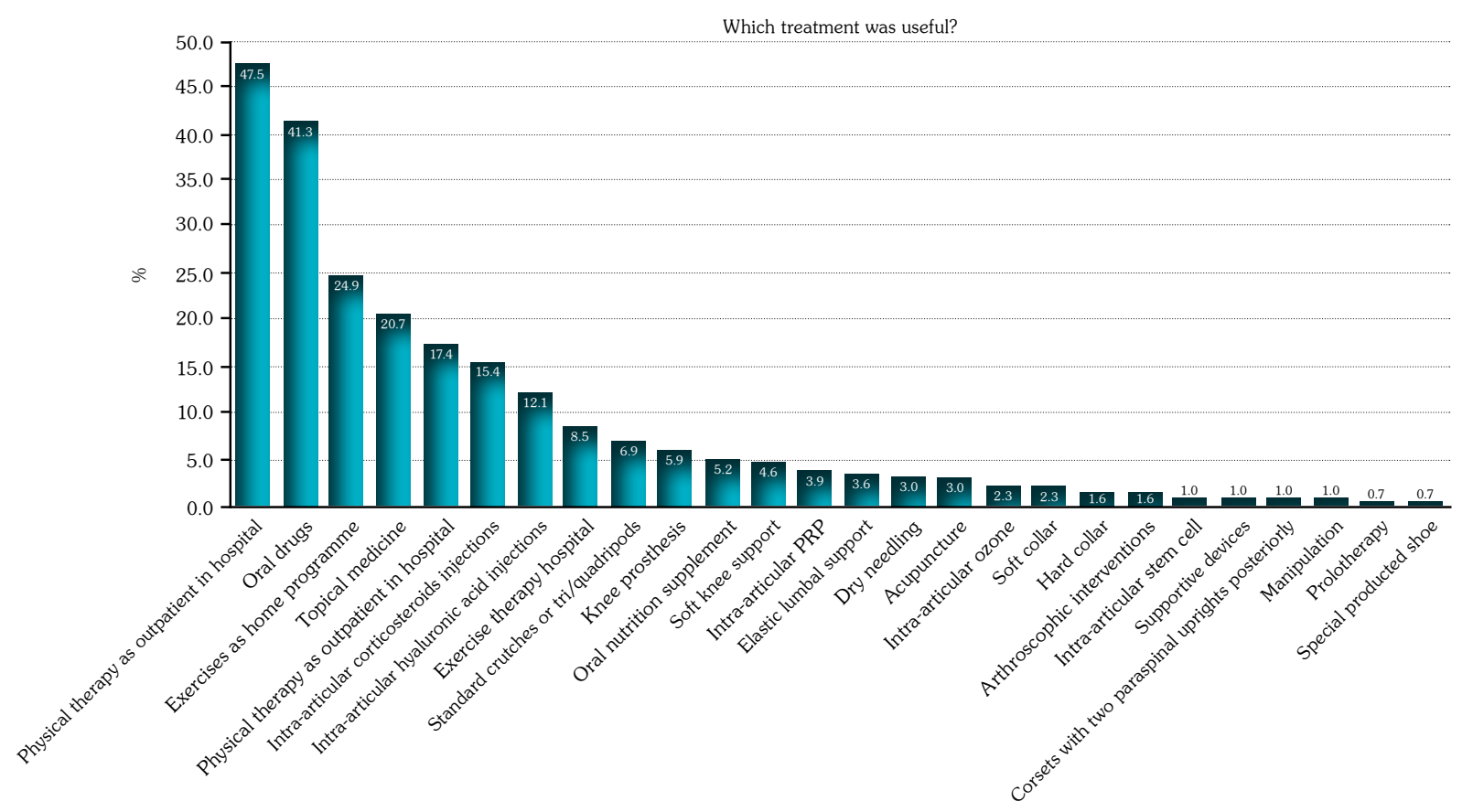

Figure 3. Useful therapeutic options stated by patients.

PRP: Platelet-rich plasma.

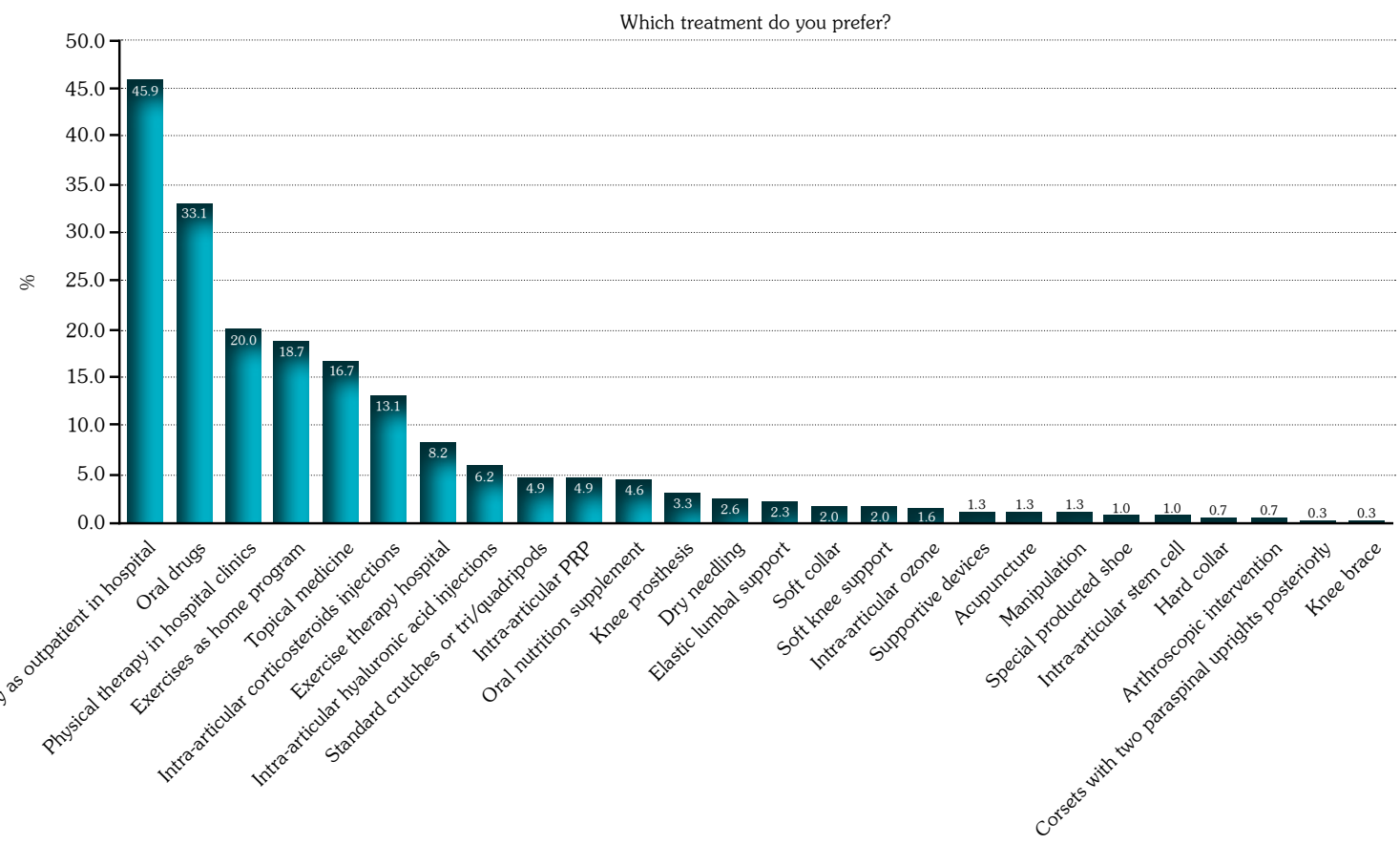

Figure 4. Preference of treatment according to the patient's choice.

PRP: Platelet-rich plasma. 


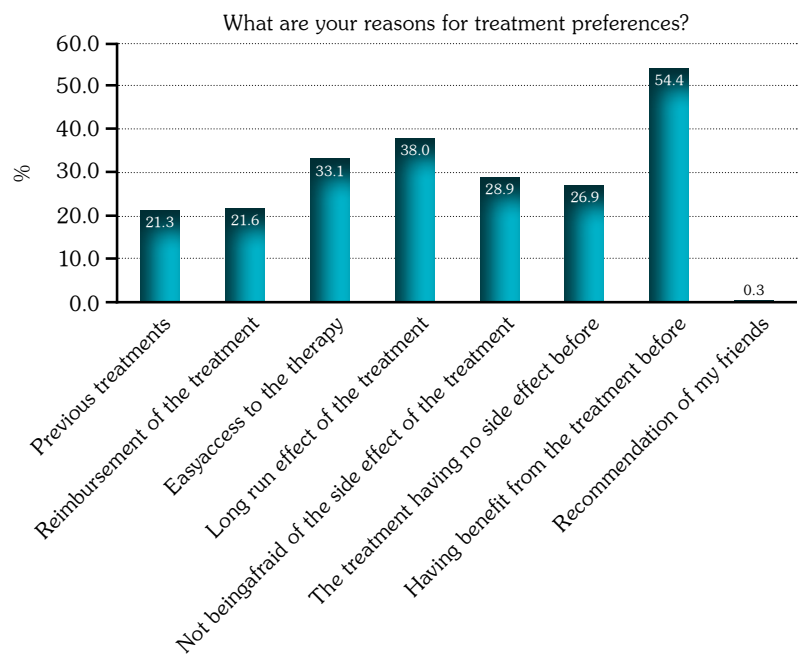

Figure 5. Reasons for treatment preferences stated by patients. majority of the patients were informed about the recommended treatments from physicians (91.8\%), friends $(20.3 \%)$, TVs $(2 \%)$, social mediainternet (1.6\%), and newspapers (0.7\%).

According to the patients, the most effective treatments was defined as outpatient physical therapy (47.5\%), oral drugs (41.3\%), homebased exercise programs (24.9\%), topical drugs (20.7\%), and inpatient physical therapy programs (17.4\%) (Figure 3). When asked about treatment preferences, nearly half of the patients preferred outpatient physical therapy program (45.9\%), oral drugs (33.1\%), and inpatient physical therapy program (20\%). The preference of the treatments in regard to patient choice is shown in Figure 4. The most common reason for the treatment preference

Table 2. Preferences of treatment choice according to sex

\begin{tabular}{|c|c|c|c|c|}
\hline & Female $(n=239)$ & Male $(n=66)$ & & \\
\hline & $\%$ & $\%$ & $\chi^{2}$ value & $p$ \\
\hline Oral drugs & 33.9 & 30.3 & 0.160 & 0.689 \\
\hline Topical medicine & 15.9 & 19.7 & 0.298 & 0.585 \\
\hline Home-based exercise program & 19.7 & 15.2 & 0.428 & 0.513 \\
\hline Outpatient physical therapy & 41.4 & 62.1 & 8.923 & 0.003 \\
\hline Intra-articular corticosteroids injections & 15.1 & 6.1 & 2.931 & 0.087 \\
\hline Inpatient physical therapy & 22.6 & 10.6 & 3.926 & 0.048 \\
\hline Exercise therapy in hospital & 9.6 & 3.0 & 2.176 & 0.140 \\
\hline
\end{tabular}

Table 3. Preferences of treatment choice according to education status

\begin{tabular}{|c|c|c|c|c|c|c|c|}
\hline & $\begin{array}{c}\text { Illiterate } \\
(\mathrm{n}=36)\end{array}$ & $\begin{array}{c}\text { Primary } \\
\text { School 1-5 } \\
(\mathrm{n}=111) \\
\end{array}$ & $\begin{array}{c}\text { Secondary } \\
\text { School 6-8 } \\
(\mathrm{n}=37)\end{array}$ & $\begin{array}{l}\text { High } \\
\text { School } \\
(\mathrm{n}=55)\end{array}$ & $\begin{array}{l}\text { University } \\
(\mathrm{n}=64)\end{array}$ & & \\
\hline & $\%$ & $\%$ & $\%$ & $\%$ & $\%$ & $\chi^{2}$ value & $p$ \\
\hline Oral drugs & 27.8 & 39.6 & 32.4 & 25.5 & 29.7 & 4.404 & 0.354 \\
\hline Topical medicine & 11.1 & 10.8 & 18.9 & 18.2 & 26.6 & 8.339 & 0.080 \\
\hline Home-based exercise & 8.3 & 14.4 & 16.2 & 25.5 & 26.6 & 8.355 & 0.079 \\
\hline Outpatient physical therapy & 38.9 & 42.3 & 48.6 & 54.5 & 48.4 & 3.198 & 0.525 \\
\hline Intra-articular steroids & 13.9 & 14.4 & 13.5 & 12.7 & 9.4 & 0.981 & 0.913 \\
\hline Inpatient physical therapy & 27.8 & 27.9 & 18.9 & 9.1 & 12.5 & 12.027 & 0.017 \\
\hline Exercise therapy in hospital & - & 9.9 & 8.1 & 7.3 & 10.9 & 7.213 & 0.125 \\
\hline
\end{tabular}


Table 4. The relationship between patients' treatment choices and disease duration

\begin{tabular}{|c|c|c|c|c|c|c|c|}
\hline & $\begin{array}{c}\text { Illiterate } \\
(\mathrm{n}=36)\end{array}$ & $\begin{array}{l}\text { Primary } \\
\text { School 1-5 } \\
(\mathrm{n}=111)\end{array}$ & $\begin{array}{c}\text { Secondary } \\
\text { School 6-8 } \\
(\mathrm{n}=37)\end{array}$ & $\begin{array}{l}\text { High } \\
\text { School } \\
(\mathrm{n}=55)\end{array}$ & $\begin{array}{l}\text { University } \\
(\mathrm{n}=64)\end{array}$ & & \\
\hline & $\%$ & $\%$ & $\%$ & $\%$ & $\%$ & $\chi^{2}$ value & $p$ \\
\hline Oral drugs & 40.4 & 27.7 & 29.5 & 30.0 & 44.4 & 5.374 & 0.251 \\
\hline Topical medicine & 17.0 & 13.8 & 14.8 & 15.0 & 26.7 & 3.953 & 0.412 \\
\hline Home-based exercise & 17.0 & 16.9 & 17.0 & 20.0 & 24.4 & 1.425 & 0.840 \\
\hline Outpatient physical therapy & 44.7 & 49.2 & 48.9 & 41.7 & 42.2 & 1.308 & 0.860 \\
\hline Intra-articular steroids & 8.5 & 9.2 & 14.8 & 15.0 & 17.8 & 2.993 & 0.559 \\
\hline Inpatient physical therapy & 10.6 & 21.5 & 21.6 & 21.7 & 22.2 & 3.053 & 0.549 \\
\hline Exercise therapy in hospital & 6.4 & 10.8 & 8.0 & 3.3 & 13.3 & 4.489 & 0.344 \\
\hline
\end{tabular}

was previous benefits of the treatment (54.4\%). Long-term positive effects (38\%), easy access to treatment (33.1\%), and concerns about side effects of drugs (28.9\%) were also accounted for treatment preference. The distribution of the reasons for patients' treatment preference is shown in Figure 5.

In terms of the preference of hospitalization (inpatient/outpatient physical therapy program), male patients preferred outpatient physical therapy program, while female patients preferred hospitalization (Table 2). In terms of education status of the patients, the illiterate and primary school graduates preferred inpatient program than the others (Table 3). The reason for the medical care procedure choices of the patients were similar between both sexes and in regard to the presence of chronic diseases ( $p>0.05$, data not shown). However, considering the education status, primary school group made a choice of treatments covered by insurance with a higher rate. The relationship between the patients' treatment choice and disease duration was also analyzed and no correlation was found between these parameters (Table 4).

\section{DISCUSSION}

The results of our study showed that oral and topical drugs, home-based exercise programs, and outpatient physical therapy program were the most preferred treatments by the patients with OA. Outpatient physical therapy programs, oral drugs, and exercises were also found to be useful. Physical therapy medicine and rehabilitation program of OA patients with therapeutic and individually designed exercise programs, implementation of physical therapy modalities for the restoration of physical function and movement were not only a registered treatment, but also preferred ones by our OA patients.

The current treatments of $\mathrm{OA}$ are mostly on a symptomatic approach, which includes some symptom-relieving preventive, pharmacological and non-pharmacological modalities. ${ }^{5}$ Therefore, the patient's needs and preferences would guide clinicians while planning the treatment, and knowledge about preferences is important in terms of clinical and policy decisions, patient compliance and treatment success. ${ }^{12}$ There are several decision aids developed for clinicians to help them to discuss non-operative treatment options with their patients having OA-related pain. Lindblad et al. ${ }^{16}$ reported that the decision aids should be combined with similar systematic reviews and tools on other types of pain to inform future guideline development. Currently, clinicians are encouraged to practice evidence-based medicine, as well as patient-centered medicine. Siminoff ${ }^{17}$ clearly suggested that clinicians engaged in evidence-based medicine needed to acknowledge the social and cultural factors which affect the health-care encounter and expand the paradigm of evidence-based medicine to incorporate sociocultural influences more explicitly. According to Hiligsmann et al., ${ }^{12}$ given the significant challenges and lack of therapeutic options for OA, it is not surprising that several 
stated-preference studies were conducted to elicit preferences for OA treatment. Medical drug treatments are still the most commonly used option in OA treatment. However, exercises and physical therapy are also highly recommended. ${ }^{5}$ All of these therapies and modalities were found to be preferable in our study group.

The most important factors in treatment preferences for patients were previously defined as benefit/risk assessment and treatment to be covered by insurance. ${ }^{18,19}$ These studies showed that patients were mainly concerned about potency and risk of therapy, and had also a desire to participate in the treatment decision process. Regarding the physician preferences, pain relief, improvement in function, risk of serious side effects, the financial burden to the patient were the leading reasons. ${ }^{18,19}$ Sometimes, patients were more willing than physicians to accept risks. To reduce the preference gap and achieve treatment goals, physicians must better understand their patients' preferences. ${ }^{7}$ In our study, the most common reason for patients' treatment preferences was the previous benefit from treatment, followed by long-term positive effects, easy access to treatment, and concerns about side effects of drugs. In addition, the most important reason for choosing treatment type was the effectiveness mostly. Patients also prefer the wide and long-spectrum effective treatments and are also worry about the side effects of drugs. ${ }^{20,21}$ In addition, one of the most commonly preferred treatments was home-based exercise program which indicates the importance of both accessibility and effectiveness of the treatment while making a treatment choice. According to evidence synthesis studies, substantial evidence regarding the benefits of strength exercises for the treatment of exercises was reported previously by several authors. ${ }^{22}$

Most treatment modalities are paid by the government within the scope of insurance in Turkey, and the reimbursement of the treatment was not the leading cause in preference reasons according to our patients, contrary to previous data. ${ }^{12,17,19-23}$ However, the preferences of treatment choice in regard to education status of the patients indicated that the illiterate and primary school graduates preferred more inpatient physical therapy than the others. This can be due to economic aspect of sociocultural profile of patients and uneasiness of transportation, etc. Besides, most of the patients preferred insurance covered the treatments with a higher rate. This can be explicable by the economic status of the patients. Majority of the patients were retired and the patients who were working got inadequate salary or retirement pension. Fortunately, In Turkey, social security system covers most therapies of OA. Even if it was the prevalent therapy and recommended by the physicians, our patients were not willing to receive the uncovered treatment modalities. Treatment preferences according to sex were not studied in OA patients before; however, some previous studies indicated that female patients preferred less knee replacement surgeries than males. ${ }^{20,23}$ In our study, female patients preferred hospitalization, while male patients preferred outpatient physical therapy. It may be due to the working status of the male patients. Also, majority of females were housewives and they might prefer the inpatient therapies for a complete rest and escape from houseworks.

One of the major challenges in healthcare services worldwide is ensuring patients to fully comply with their treatments. Medication adherence for patients with OA is complex, involving motivators which would fluctuate the impact on individuals at different points along the disease progression. It is perceived as a balance between the willingness and preference to take medications with the alternative being toleration of symptoms. ${ }^{24}$ Most methods used for increasing medical adherence require combinations of behavioral interventions and reinforcements in addition to increasing the convenience of care, providing educational information about the patient's condition and the treatment, and other forms of supervision or attention. ${ }^{25}$ To improve adherence to treatment, there are various strategies. The evaluation of individual differences of patients and their treatment preferences seem to be crucial for planning the treatment and preventing non-adherence to treatment. Patient-centered care that emphasizes the patient's experience with their illness and inviting patients to be active participants in their care should be considered in planning treatment options for patients with OA. ${ }^{26,27}$ Preference- 
sensitive treatments are those in which there are trade-offs between health benefits and risks. The patient's consideration of these factors is of utmost importance in the eventual utilization of such services. In the OA field, stated preference studies have primarily been conducted to assess the preferences for the characteristics of OA drug treatment and data have been suggested to be used in determining the treatment approaches. ${ }^{12}$

There are some limitations to this study. First, although self-reported questionnaires are the most commonly used methods, they may lead to the overestimation of patient preference. Second, there is no standard or validated questionnaire form or instrument to assess patient treatment preferences in the literature, and the one used in this study was prepared by the PMR specialists who were experienced both in the treatment of $\mathrm{OA}$ and geriatric patient group. Third, all the patients diagnosed with OA were enrolled without considering specific localization of the disease which may have an impact on therapeutic choice of preferences. In recent years, numerous studies have been performed on various diseases to assess patient preferences. To date, studies examining patient preferences in OA treatment have usually addressed to drug preferences, surgical options, and physical activity options. The main strengths of this study are that all treatment options consisting of complementary therapies and new treatment methods in the literature were questioned, which may add a value to our data. Another important issue is that our study has a multi-center design conducted in different centers with a high number of patients. To the best of our knowledge, this is the first multicenter, descriptive study carried out in Turkey which evaluated the treatment preferences in patients with OA.

In conclusion, the treatment preferences of our patient group were mostly drugs, outpatient and inpatient physical therapy programs, and home-based exercises depending on the reasons such as previous benefit from treatment, long-term effects, easily access to treatment, and concerns about side effects. Since preference-sensitive treatments may play a critical role in adherence, particularly in chronic diseases such as OA, previous treatments and patient preferences can be checked by the clinicians to anticipate and improve adherence behavior before the treatment planning.

\section{Declaration of conflicting interests}

The authors declared no conflicts of interest with respect to the authorship and/or publication of this article.

\section{Funding}

The authors received no financial support for the research and/or authorship of this article.

\section{REFERENCES}

1. Damen J, van Rijn RM, Emans PJ, Hilberdink WKHA, Wesseling J, Oei EHG, et al. Prevalence and development of hip and knee osteoarthritis according to American College of Rheumatology criteria in the CHECK cohort. Arthritis Res Ther 2019;21:4.

2. Swain S, Sarmanova A, Mallen C, Kuo CF, Coupland $\mathrm{C}$, Doherty $\mathrm{M}$, et al. Trends in incidence and prevalence of osteoarthritis in the United Kingdom: Findings from the Clinical Practice Research Datalink (CPRD). Osteoarthritis Cartilage 2020;28:792-801.

3. Brennan-Olsen SL, Cook S, Leech MT, Bowe SJ, Kowal P, Naidoo N, et al. Prevalence of arthritis according to age, sex and socioeconomic status in six low and middle income countries: analysis of data from the World Health Organization study on global AGEing and adult health (SAGE) Wave 1. BMC Musculoskelet Disord 2017;18:271.

4. GBD 2017 Disease and Injury Incidence and Prevalence Collaborators. Global, regional, and national incidence, prevalence, and years lived with disability for 354 diseases and injuries for 195 countries and territories, 1990-2017: A systematic analysis for the Global Burden of Disease Study 2017. Lancet 2018;392:1789-858.

5. Tuncer T, Cay FH, Altan L, Gurer G, Kacar C, Ozcakir S, et al. 2017 update of the Turkish League Against Rheumatism (TLAR) evidence-based recommendations for the management of knee osteoarthritis. Rheumatol Int 2018;38:1315-31.

6. Hermann W, Lambova S, Muller-Ladner U. Current treatment options for osteoarthritis. Curr Rheumatol Rev 2018;14:108-16.

7. Byun JH, Kwon SH, Lee JE, Cheon JE, Jang EJ, Lee EK. Comparison of benefit-risk preferences of patients and physicians regarding cyclooxygenase- 2 inhibitors using discrete choice experiments. Patient Prefer Adherence 2016;10:641-50.

8. Coxon D, Frisher M, Jinks C, Jordan K, Paskins Z, Peat $G$. The relative importance of perceived doctor's attitude on the decision to consult for symptomatic osteoarthritis: A choice-based conjoint analysis study. BMJ Open 2015;5:e009625. 
9. Pinto D, Bockenholt U, Lee J, Chang RW, Sharma L, Finn DJ, et al. Preferences for physical activity: A conjoint analysis involving people with chronic knee pain. Osteoarthritis Cartilage 2019;27:240-7.

10. Moorman CT 3rd, Kirwan T, Share J, Vannabouathong C. Patient preferences regarding surgical interventions for knee osteoarthritis. Clin Med Insights Arthritis Musculoskelet Disord 2017;10:1179544117732039.

11. Miller KA, Baier Manwell LM, Rabago D. Multimodal care for knee and hip osteoarthritis: A pilot feasibility study of a novel approach to a common problem. WMJ 2020;119:44-7.

12. Hiligsmann M, Pinto D, Dennison E, Al-Daghri N, Beaudart C, Branco J, et al. Patients' preferences for osteoarthritis treatment: The value of statedpreference studies. Aging Clin Exp Res 2019;31:1-3.

13. Clark MD, Determann D, Petrou S, Moro D, de Bekker-Grob EW. Discrete choice experiments in health economics: A review of the literature. Pharmacoeconomics 2014;32:883-902.

14. Altman R, Asch E, Bloch D, Bole G, Borenstein D, Brandt $\mathrm{K}$, et al. Development of criteria for the classification and reporting of osteoarthritis. Classification of osteoarthritis of the knee. Diagnostic and Therapeutic Criteria Committee of the American Rheumatism Association. Arthritis Rheum 1986;29:1039-49.

15. Altman R, Alarcón G, Appelrouth D, Bloch D, Borenstein D, Brandt K, et al. The American College of Rheumatology criteria for the classification and reporting of osteoarthritis of the hip. Arthritis Rheum 1991;34:505-14.

16. Lindblad AJ, McCormack J, Korownyk CS, Kolber MR, Ton J, Perry D, et al. PEER simplified decision aid: Osteoarthritis treatment options in primary care. Can Fam Physician 2020;66:191-3.

17. Siminoff LA. Incorporating patient and family preferences into evidence-based medicine. BMC Med Inform Decis Mak 2013;13 Suppl 3:S6.

18. Berchi C, Degieux P, Halhol H, Danel B, Bennani $\mathrm{M}$, Philippe C. Impact of falling reimbursement rates on physician preferences regarding drug therapy for osteoarthritis using a discrete choice experiment. Int $\mathrm{J}$ Pharm Pract 2016;24:114-22.

19. Laba TL, Brien JA, Fransen M, Jan S. Patient preferences for adherence to treatment for osteoarthritis: The MEdication Decisions in Osteoarthritis Study (MEDOS). BMC Musculoskelet Disord 2013;14:160.

20. Selten EM, Vriezekolk JE, Geenen R, van der Laan WH, van der Meulen-Dilling RG, Nijhof MW, et al. Reasons for treatment choices in knee and hip osteoarthritis: A qualitative study. Arthritis Care Res (Hoboken) 2016;68:1260-7.

21. Smith TO, Purdy R, Lister S, Salter C, Fleetcroft R, Conaghan PG. Attitudes of people with osteoarthritis towards their conservative management: A systematic review and meta-ethnography. Rheumatol Int 2014;34:299-313.

22. Imoto AM, Pardo JP, Brosseau L, Taki J, Desjardins $\mathrm{B}$, Thevenot $\mathrm{O}$, et al. Evidence synthesis of types and intensity of therapeutic land-based exercises to reduce pain in individuals with knee osteoarthritis. Rheumatol Int 2019;39:1159-79.

23. Vina ER, Cloonan YK, Ibrahim SA, Hannon MJ, Boudreau RM, Kwoh CK. Race, sex, and total knee replacement consideration: Role of social support. Arthritis Care Res (Hoboken) 2013;65:1103-11.

24. Dockerty T, Latham SK, Smith TO. Why don't patients take their analgesics? A meta-ethnography assessing the perceptions of medication adherence in patients with osteoarthritis. Rheumatol Int 2016;36:731-9.

25. Ylldı V, Özdemir O, Gökçe Kutsal Y. Medication nonadherence in eldery and recommendations to imrove adherence. Turkish Journal of Geriatrics 2017;20:344-50.

26. Epstein RM. The science of patient-centered care. J Fam Pract 2000;49:805-7.

27. Gill VT. Patient "Demand" for medical interventions: Exerting pressure for an offer in a primary care clinic visit. Research on Language and Social Interaction 2005;38:451-79. 